\title{
Treating insomnia with medications
}

\author{
J. F. Pagel ${ }^{1,4^{*}}$ (D), Seithikurippu R. Pandi-Perumal ${ }^{2}$ and Jaime M. Monti ${ }^{3}$
}

\begin{abstract}
Insomnia is a conspicuous problem in modern $24 \mathrm{~h}$ society. In this brief overview, medications used to treat insomnia such as hypnotics, sedatives, medications inducing sedation as a side effect, medications directed at the sleep-associated circadian neuroendocrine system, and agents utilized in treating insomnia-inducing sleep diagnoses such as restless leg syndrome are discussed. The newer GABA-effective hypnotics are the only medications with demonstrated effectiveness in treating chronic insomnia with the majority of evidence supporting treatment efficacy for cognitive-behavioral therapy and short acting GABA-receptor agonists. In patients with comorbid insomnia the use of hypnotics can improve outcomes and potentially reduce morbidity and mortality associated with the use of more toxic medications. Except in individuals whose insomnia is secondary to circadian disturbance, mood disorder/depression and/or restless leg syndrome, there is minimal evidence supporting the efficacy of other medications used to treat insomnia despite their widespread use. Sedatives and other medications used off-label for sedative side-effects are a contributing factor to drug induced hypersomnolence, a factor in more than $30 \%$ of motor accident deaths. Hypnotic medications with low toxicity, addictive potential, minimal next day sleepiness, and an otherwise benign side-effect profile can be utilized safely and effectively to treat and improve function and quality of life for patients suffering from insomnia. These are the agents that should be exclusively classified as hypnotics and utilized to induce sleep when medications are required to treat the complaint of insomnia. Other pharmacological agents producing sedation (sedatives and agents used off-label for sedative side-effects) should be used cautiously for the treatment of insomnia due to the increased risk of next day sleepiness as well as for known toxicities and adverse side effects.
\end{abstract}

Keywords: Insomnia, Medications, Hypnotics, Sedatives, Benzodiazepine

\section{Introduction}

Insomnia, defined as the subjective perception of difficulty with sleep initiation, duration, consolidation, or quality that occurs despite adequate opportunity for sleep, is a conspicuous problem in modern 24-h society (Sateia et al. 2017). Episodes of acute or transient insomnia each year affect $>80 \%$ of adults. Chronic insomnia (> 3 months in duration) includes difficulty falling asleep, insufficient sleep, or perceived nonrestorative sleep producing daytime complaints of somnolence, fatigue, irritability, or difficulty concentrating and performing everyday tasks, and has a population prevalence of approximately $14 \%$ (Hauri 2005; NIH State of the Science Conference Statement on Manifestations and Management of Chronic Insomnia in Adults Statement, Journal

\footnotetext{
* Correspondence: pueo34@gmail.com

${ }^{1}$ University of Colorado School of Medicine, Couthern Colorado Residency Program, Pueblo, CO, USA

${ }^{4}$ Rocky Mountain Sleep, 1306 Fortino Blvd, Pueblo, CO 81008, USA Full list of author information is available at the end of the article
}

of Clinical Sleep Medicine 2005). Chronic insomnia is significantly associated with a decrease in quality of life measures, the exacerbation of co-morbid diagnoses, and an increased likely-hood for developing mood disorders / de[ression (Sateia et al. 2017). While there are dozens of insomnia-associated sleep diagnoses, any medical or psychiatric disorder or environmental stress that produces nighttime discomfort is likely to induce insomnia. Medications for treating insomnia are classified as hypnotics, sedatives, medications inducing sedation as a side effect, medications directed at the sleep-associated circadian neuroendocrine system, and agents utilized in treating insomnia-inducing sleep diagnoses such as restless leg syndrome (RLS) (Curry et al. 2006; Bhat et al. 2008).

\section{Sleep hygiene and cognitive behavioral therapies} Sleep behaviors must be addressed for any patient presenting with insomnia. Insomnia can be treated without medications, using sleep hygiene combined with 
cognitive and behavioral therapies (CBT). This approach avoids potential drug side effects and toxicities and has shown long-term persistence in treating chronic insomnia that can be superior to results obtained using drug therapies (Morin 2005). Sleep hygiene refers to environmental factors, dietary approaches, drugs, and a lack of required sleep facilitating approaches that can induce insomnia. Insomnia inducing drugs include caffeine, nicotine, weight loss preparations, and activating agents of both prescription and abuse. CBT extends sleep hygiene into the use of sleep facilitating cognitive and behavioral approaches for treating insomnia (Finley and Perlis 2014). CBT has proven its usefulness in treating chronic insomnia, working best when administered by a trained provider over several extended visits (Riemann and Perlis 2009). Insomnia treatment can be limited to the use of hygiene and CBT, but such an approach has clear limitations. Behavioral approaches are rarely effective in treating acute and transient episodes of insomnia and have limited usefulness in treating comorbid insomnia. CBT requires patient interest and effort and as a clinical approach is unavailable to many affected individuals due to both cost and limitations in provider access (Lichstein et al. 2005). Even when appropriately utilized, CBT does not work for every patient (Trauer et al. 2015).

\section{Sleep neurophysiology}

From a behavioral stand-point, sleep is a complex, reversible behavioral state of perceptual disengagement from, and unresponsiveness to, the environment (Carskadon and Dement, 2011). To this point, no specific anatomical site or required neurochemical trigger has been identified. Neuroanatomical structures in the CNS are affected globally by sleep associated changes in neurochemical, electrophysiological and neuroendocrine systems.

\section{The neurochemistry of sleep}

Sleep is a global state involving multiple factors and systems, with no single neurochemical identified as necessary for modulating sleep (Brown et al. 2012). In most cases, the CNS effects of drugs can be ascribed to primary effects on specific neurotransmitters and neuromodulators. Most hypnotics affect GABA, the primary negative neurotransmitter in the CNS, or affect specific neuromodulators of GABA that include serotonin, acetylcholine, and dopamine (Pagel 2017). Other drugs, particularly those classified as sedatives, induce sedation by antagonizing one or more of the central activating neuromodulators. These activating neuromodulators include serotonin, norepinephrine, histamine, acetylcholine, dopamine, and orexin. Other substances known to affect sleep include adenosine, substance P, corticotrophin releasing factor (CRF), thyrotrophin releasing factor (TRF), vasoactive intestinal peptide (VIP), neurotensin, muramyl peptides, endotoxins, cytokines [interleukin-1B, tumor necrosis factor- $\alpha$ ], interleukin $1 \mathrm{~B}$, tumor necrosis factor- $\alpha$ (TNF $\alpha)$, prostaglandin D2 (PGD2) and melanin concentrating hormone $(\mathrm{MCH})$ (García-García et al. 2009; Urade and Hayaishi 2011; Pabst et al. 1999). Sedation is among the most common effects and/or side effects of prescription medications. The list of agents inducing sedation as an effect and/or side effect is extensive and includes most medication classifications (Table 1) (Pagel 2017). Sedation is commonly induced by over the counter (OTC) preparations (particularly anti-histamines), and commonly used drugs of abuse such as cannibis and ethanol. When the use of

Table 1 Medications Not Classified As Sedative/Hypnotics Inducing Daytime Sleepiness As A Side Effect

\begin{tabular}{ll}
\hline Medication Class & Neurochemical Basis For Sleepiness \\
\hline Antiparkinsonian Agents & Dopamine Receptor Agonists \\
Antimuscarinic/ Antispasmodic & Varied effects \\
Skeletal Muscle Relaxants & Varied Effects \\
$\begin{array}{l}\text { Alpha- Adrenergic } \\
\text { Blocking Agents }\end{array}$ & Alpha-1 Adrenergic Antagonists \\
Beta-Adrenergic & Beta Adrenergic Antagonists \\
Blocking Agents & \\
Gamma-Hydroxy-Butyrate & GABA Agonist \\
Opiate Agonists & Opioid Receptor Agonists \\
& (General Cns Depression) \\
Opiate Partial Agonists & Opioid Receptor Agonists \\
& (General Cns Depression) \\
Anticonvulsants & \\
Barbiturates & GABA Agonist \\
-Benzodiazepines & GABA Agonist \\
- Hydantoins & Neurotransmitter effect poorly defined - \\
& electrophysiolic? \\
- Succinimides & Neurotransmitter effect poorly defined - \\
& electrophysiolic?
\end{tabular}

Other Antidepressants

\begin{tabular}{|c|c|}
\hline - Maoi & Norepinephrine, 5ht \& Dopamine \\
\hline - Ssri & Serotonin Uptake Inhibition \\
\hline -Agents With Mixed Effects & Serotonin, Dopamine, \& Norepinephrine \\
\hline Other Antipsychotics & $\begin{array}{l}\text { Dopamine Receptor Blockage, Varied } \\
\text { Effects On Histaminic, Cholinergic } \\
\text { And Alpha Adrenergic Receptors }\end{array}$ \\
\hline $\begin{array}{l}\text { Other Benzodiazepines } \\
\text { Not Used For Sedation }\end{array}$ & GABA Agonist \\
\hline $\begin{array}{l}\text { Anxiolytics, misc. Sedative } \\
\& \text { hypnotics }\end{array}$ & GABA Agonist, Varied Effects \\
\hline Antitussives & Neurotransmitter Effect Poorly Defined \\
\hline Antidiarrhea agents & $\begin{array}{l}\text { Neurotransmitter Effect Poorly Defined - } \\
\text { Opioid In Some Cases }\end{array}$ \\
\hline Antiemetics & Antihistamine \& Varied Effects \\
\hline $\begin{array}{l}\text { Genitourinary Smooth } \\
\text { Muscle Relaxants }\end{array}$ & Neurotransmitter Effect Poorly Defined \\
\hline
\end{tabular}


these agents is coupled with the use of sedating prescriptions, additive sedation, toxicity, and side-effects increase the danger of life-threatening over-dose (National Institue on Drug Abuse: National Institutes of Health 2015).

\section{The electrophysiology of sleep}

In the clinical laboratory, sleep is defined by its electroencephalography (EEG) in concert with electromyography (EMG), electrooculography (EOG) and other telemetry. Using polysomnographic recordings, sleep can be classified into rapid eye movement (REM) sleep and non-rapid eye movement (NREM) sleep. The NREM sleep is further classified into 3 sleep stages namely Stage N1 sleep, Stage N2 sleep, and stage N3 sleep (also known as slow wave sleep, delta sleep or deep sleep), based primarily on the occurrence of synchronous physiologic EEG potentials. Drowsy awake with eyes closed is defined by the presence of alpha - the frequency with the most power on spectral analysis. Sleep onset (Stage N1) is generally defined as occurring at the point in which there is a decline of alpha rhythm (9$11 \mathrm{~Hz}$ ) to less than $50 \%$ of the recorded epoch. Stage N2 sleep is denoted by bursts of sleep spindles at sigma frequency (11-16 Hz) and K-complex events - electrophysiological down states known to negatively affect the general tendency of neurons to develop spike potential activity (Cash et al. 2009). Deep sleep (stage N3 sleep) occurs in association with delta frequency oscillations (0.5$1.5 \mathrm{~Hz}$ ). REM sleep is characterized by bursts of intracranial theta $(5-8 \mathrm{~Hz})$, with alpha and gamma oscillations noted in scalp recordings, associated with conjugate eye movements and diminished skeletal EMG activity. Medications producing CNS-related behavioral effects generally affect background EEG frequencies (Mamdema and Danhof 1992). In most cases, a consistent pattern of EEG change produced by a drug is associated with a consistent pattern of behavioral change (Hermann and Schaerer 1986). Psychoactive drugs produce alterations in physiologic EEG rhythms consistent across therapeutic classifications and utilized to predict the behavioral activity of new preparations, drug interactions and toxicities (Blume 2006) (Table 2).

\section{The neuroendocrinology of sleep}

Sleep regulation is a complex interaction between the homeostatic and the endogenous circadian processes (Borbély et al. 2016). The circadian processes of sleep are largely controlled by the suprachiasmatic nucleus (SCN) in the hypothalamus (Dai et al. 1998; Hofman et al. 1996; Swaab et al. 1985; Vimal et al. 2009). This internal human clock responds to external factors with the greatest influence being exposure to light/dark (LD) cycle (Lewy et al. 1980; Morin 2015). The other important element to the timing of the sleep/wake cycle is the endogenously produced neural hormone melatonin, produced by the pineal gland in response to signals from the SCN. Melatonin can induce sedation, an effect sometimes utilized to assist children in tolerating medical procedures (Johnson et al. 2002). In addition to regulation of the sleep/wake cycle, body temperature and numerous other processes vary with circadian rhythm (Sack et al. 2007). Externally introduced

Table 2 Consistent quantitative alteration in physiologic EEG frequencies induced by psychoactive medications

\begin{tabular}{|c|c|c|c|c|c|c|}
\hline \multirow[t]{2}{*}{ Class of drugs } & \multicolumn{5}{|c|}{ Eeg frequencies } & \multirow[t]{2}{*}{ Treatment indications } \\
\hline & $\begin{array}{l}\text { Delta } \\
(0.5-1.5 \mathrm{~Hz})\end{array}$ & $\begin{array}{l}\text { Theta } \\
(5.5-8.5 \mathrm{~Hz})\end{array}$ & $\begin{array}{l}\text { Alpha } \\
(8.5-11 \mathrm{~Hz})\end{array}$ & $\begin{array}{l}\text { Sigma } \\
(12-16 \mathrm{~Hz})\end{array}$ & $\begin{array}{l}\text { Beta/Gamma } \\
(21-32 \mathrm{~Hz})\end{array}$ & \\
\hline Benzodiazepines (BZDs) & & & Decrease & Increase & Increase & $\begin{array}{l}\text { Anxiety } \\
\text { Sedation }\end{array}$ \\
\hline Barbiturates & & & & Increase & Increase & $\begin{array}{l}\text { Anxiety } \\
\text { Sedation } \\
\text { Epilepsy }\end{array}$ \\
\hline Tricyclic Antidepressants (TCAs) & decrease & Decrease & & & Increase & Depression \\
\hline SSRI Antidepressants & decrease & & Increase & & & $\begin{array}{l}\text { Depression } \\
\text { Anxiety } \\
\text { OCD }\end{array}$ \\
\hline Amphetamines & decrease & Decrease & & & increase & $\begin{array}{l}\text { Somnolence } \\
\text { Narcolepsy } \\
\text { AD/HD }\end{array}$ \\
\hline Opiates & increase & & decrease & & & Pain \\
\hline $\begin{array}{l}\text { Anticonvulsants } \\
\text { Phenytoin, valproate, carbamazepine }\end{array}$ & & increase & & & & Epilepsy \\
\hline Gamma hydroxy butyrate (GHB) & increase & & & & & $\begin{array}{l}\text { Cataplexy } \\
\text { Narcolepsy }\end{array}$ \\
\hline Classic Neuroleptics & & increase & decrease & decrease & & $\begin{array}{l}\text { Schizophrenia } \\
\text { Psychosis }\end{array}$ \\
\hline
\end{tabular}


melatonin can be utilized to reset circadian rhythms of sleep and body core temperature through its actions on the SCN (Abbott et al. 2014).

\section{The optimal hypnotic}

Sleep-inducing drugs (hypnotics) are medications specifically designed to induce sleepiness directly after intake. Optimal agents affect cognitive performance during this period while inducing minimal sleepiness in the waking day after use. An optimal hypnotic would have low toxicity and addictive potential, as well a minimal side effect profile (Oswald 1970). Among the first hypnotics, and an agent still in use is chloral hydrate - the original "Mickey Finn" - slipped into the drinks of unsuspecting marks for the purposes of criminal activity. Unfortunately, this medication is difficult to use since the LD-50 (potentially fatal dose) is quite close to the therapeutic dose. In the years leading up to the 1970's, rapidly acting barbiturates were commonly utilized for their hypnotic effects. Unfortunately, these medications, also drugs of abuse, had a significant danger of overdose and contributed to an era that was characterized in part by deaths due to overdoses of sleeping pills. These medications and similar barbiturate-like medications [Methaqualone (Quaalude, Sopor) Glutethimide (Doriden), Ethchlorvynol (Placidyl), Methyprylon (Nodudar)] have limited availability and are rarely used due to limited efficacy, cognitive effects, the potential for abuse and lethal toxicity associated with overdose (Oswald 1970). Today their primary therapeutic uses include executions and facilitated euthanasia (Lossignol 2008).

Most currently utilized hypnotics affect the widely dispersed negative neurotransmitter GABA. In the 1970's benzodiazepines (GABA agonists) were first marketed as hypnotics. Some of these agents had an extremely short duration of action [Triazolam (Halcion)]. While this agent-induced minimal next day somnolence, use was associated with daytime memory impairment, particularly at higher dosages (Roehrs et al. 2000; Adam and Oswald
1989). In the 1990's newer agents were developed and marketed that had selective effects on GABA receptors including Zolpidem (Ambien), Zaleplon (Sonata), Eszopiclone (Estorra) and Indiplon. While all hypnotics have abuse potential for individuals with addictive histories and personalities, these agents have been noted to have minimal additive potential (Hajak et al. 2003). These agents are less likely to have deleterious side effects than most OTC treatments for insomnia, however, with increased use, more side effects including next effects on driving have been reported. This effect as well as next day rebound insomnia has particularly been reported for higher doses of zolpidem (Verster et al. 2002). In many cases, MVA's occurred in the period of somnolence and cognitive impairment during the first few hours after ingestion. Comparatively normal results on psychomotor tests can be obtained $3.25 \mathrm{~h}$. after zaleplon ingestion and $6.25 \mathrm{~h}$. after zopiclone ingestion (Paul et al. 2003). While these agents have excellent efficacy with minimal side effects, at higher doses these agents can exhibit benzodiazepine-like effects. Idiosyncratic reactions of persistent daytime somnolence and/or memory loss have been reported. Some patients will report next day sedation after the nighttime use of these agents, as well as demonstrate an increased error rate in driving tests (Verster et al. 2007). Such information was forthcoming only after these drugs became generic and widely utilized in clinical practice. Most sedating drugs if adopted into such widespread use would also be at least as likely to demonstrate epidemiological effects on MVA's and MVA associated deaths. In the elderly, chronic use of sedating drugs (particularly those with anti-cholinergic side effects) can be associated with an increased risk for falls, and confusion (American Geriatrics Society 2015). Reported next day sleepiness and other side effects associated with hypnotic use are summarized in Table 3.

The newer GABA-effective hypnotics are the only medications with demonstrated effectiveness in treating chronic insomnia (NIH State of the Science Conference

Table 3 Hypnotics - Agents Utilized To Induce Sleep With Minimal Next Day Sleepiness After Used Based On Pharmacodynamics, Clinical Trials, And/Or Performance Testing

\begin{tabular}{|c|c|c|c|}
\hline Drug \& Class & 1/2 Life & Next Day Sleepiness [Clinical Trials] & Toxicity And/Or Significant Side Effects \\
\hline $\begin{array}{l}\text { Short acting gaba agonist } \\
\text { - triazolem }\end{array}$ & $1-2 \mathrm{HR}$ & $\begin{array}{l}\text { Anecdotal and per survey } \\
\text { [placebo } \\
\text { Equivalent] }\end{array}$ & Antegrade Amnesia, Confusion At Higher Dose \\
\hline $\begin{array}{l}\text { GABA selective agents } \\
\text { - zaleplon }\end{array}$ & $1 \mathrm{HR}$. & $\begin{array}{l}\text { [Placebo } \\
\text { Equivalent] }\end{array}$ & $\begin{array}{l}\text { No consistent reports } \\
\text { [not in widespread use] }\end{array}$ \\
\hline Zolpidem & $1.5 \mathrm{HR}$. & $\begin{array}{l}\text { Anecdotal [placebo } \\
\text { Equivalent] } \\
\text { Per survey when dosed outside } \\
\text { pharmacodynamic profile and in the elderly }\end{array}$ & $\begin{array}{l}\text { Symptomatic } \\
\text { Parasomnias, } \\
\text { Next night rebound insomnia }\end{array}$ \\
\hline Eszopiclone & $6 \mathrm{HR}$. & $\begin{array}{l}\text { Anecdotal } \\
\text { [placebo } \\
\text { Equivalent] }\end{array}$ & $\begin{array}{l}\text { Possible Parasomnia Associations } \\
\text { [Agent Not In Widespread Generic Use] }\end{array}$ \\
\hline
\end{tabular}


Statement on Manifestations and Management of Chronic Insomnia in Adults Statement, Journal of Clinical Sleep Medicine 2005). According to the NIH, the majority of evidence supports the efficacy of cognitive-behavioral therapy and short acting benzodiazepine receptor agonists in the treatment of chronic insomnia, at least in the short term. Chronic insomnia is often, however, a lifelong illness, and the longest clinical trials for these agents have been one year in duration. These agents can be safely utilized chronically or in an "as needed" (prn) basis in individuals with both short and long term insomnia (Morin and Espie 2003; Schutte-Rodin et al. 2008). Except in individuals whose insomnia is secondary to circadian disturbance, mood disorder/depression and/or restless leg syndrome, there is minimal evidence supporting the efficacy of other medications used to treat insomnia despite their widespread use (NIH State of the Science Conference Statement on Manifestations and Management of Chronic Insomnia in Adults Statement, Journal of Clinical Sleep Medicine 2005; Morin, Medalie and Cifu 2017).

\section{Sedatives}

Sedatives induce calming and reduce arousal during waking. At the extreme end of the spectrum of use, sedative agents are utilized in anesthesia. The sedative category included the opiates, a drug class developed from the domesticated poppy with evidenced utilization from neolithic archeologic sites (5000-7000 B. C.) (Heinrich 2013). At the dawn of medicine as a specialty, among the few agents useful as a medication was laudanum - a tincture of opium that mixed with water or wine was used as a soporific even for crying infants. Most sedative drugs selectively affect specific neurotransmitters and neuromodulators in the CNS (Schwartz 2000). Multiple factors and systems are involved. Sedative drugs can exert primary effects either at the inhibitory neurotransmitter gamma-Aminobutyric acid (GABA), or on sedating neuromodulators. Others potentiate sedation by antagonizing one of the widely dispersed central activating neuromodulators: serotonin, norepinephrine, dopamine, histamine, and orexin.

Many patients suffering from chronic insomnia are hyperaroused, unable to fall asleep even after minimal sleep the night before. Treatment of this hyperarousal presenting clinically as agitation and sometimes anxiety can produce improved sleep. Unfortunately, sedation and reduced arousal are variants of the same cognitive calming effect. Because of this, sedatives induce daytime sleepiness in many users. The idea sedative agent, like the ideal hypnotic, should have low toxicity, low addiction potential, and a benign side effect profile.

Fifty years ago, longer acting benzodiazepines, particularly Diazepam (Valium) preempted the role of opiates in sedation. Some of these agents had active breakdown products that produced an extraordinarily long active half-life (11 days) (Oswald 1970). The prolonged effect is one of waking calming and sedation, associated with increased auto accidents and falls with hip fractures. Medium 1/2 life agents including alprazolam, temazepam, and lorazepam affect next day performance tests (Ray et al. 1989). The use of these agents may be associated with an increased level of next day MVA's (Ceutel 1995; Buysse 1991).

Other sedating agents affect the GABA neuromoduators - acetylcholine, dopamine, and serotonin. Most of these agents are classified as sedating antidepressants. Sedating antidepressants include the tricyclics (amitryptiline, imipramine, nortriptyline, etc.), and atypical antidepressants: Trazodone (Deseryl), and Mirtazapine (Remeron). Trazondone is among the most widely prescibed agents for inducing sleep. There are few studies addressing the efficacy this off-label approach to treating insomia, but there are more describing trazadone's significant side-effects including next day sleepiness and psychomotor impairment in the elderly (Mendelson 2005). Among the SSRI's, Paroxetine (Paxil) can induce mild sedation. Use of sedating antidepressants has been associated with declines in daytime performance, driving test performance, and an increased potential for involvement in motor vehicular accidents (Volz and Sturm 1995). Both tricyclic and atypical antidepressants are widely used as a hypnotics despite significant next day sedation (Settle 1998).

Many of the sedating medications treat hyperarousal by antagonizing the wake-producing neuromodulating systems: serotonin, norepinephrine, dopamine, histamine, and orexin. Both prescription and over the counter (OTC) agents are marketed for sedative effects produced pharmacologically by antagonizing orexin, histamine, and norepinephrine.

Antihistamines and antipsychotics induce sedation based on their antihistaminic effects (Monti et al. 2016). Over the counter sleeping pills contain sedating H-1 antihistamines, usually diphenhydramine, hydroxyzine or triprolidine (Monti and Monti 2000). These agents induce sedation with acute use, and often induce increased daytime sleepiness and cognitive impairment persisting into the day following nighttime use (O'Hanlon and Ramaekers 1995). In comparative studies, driving performance at $2.5 \mathrm{~h}$. after administration of $50 \mathrm{mg}$. of diphenhydramine is worse than in individuals with a blood alcohol concentration (BAC) of $0.1 \%$ - the level of legal intoxication in most states (Wiler et al. 2000). Nighttime drug use can produce drowsiness severe enough to affect next day performance and driving tests (Gango et al. 1989). Sedation is infrequent with $\mathrm{H} 2$ antagonists (e.g. cimetidine, ranitidine, famotidine, and nizatidine), but 
somnolence as a side effect is reproducible in susceptible individuals (White and Rumbold 1988). Sedation is a common side effect of the traditional antipsychotics, with chlorpromazine and thioridazine somewhat more sedating than haloperidol. Clinical studies have shown a high incidence of persistent sedation with clozapine (46\%) with less frequent reports of sedation with risperidone, olanzapine, sertindole and quetiapine (Monti et al. 2016). The sedation associated with these agents is most likely associated with their known effects on histaminic receptors.

Doxepin, a sedating psychotropic agent with pronounced histamine $(\mathrm{H}-1)$ receptor antagonism exerts at least part of its effects by antagonizing orexin (Krystal et al. 2013). Suvorexant, is an orexin antagonist designed to lower waking arousal (Norman and Anderson 2016). Currently, it is being heavily marketed as a hypnotic (Rhyne and Anderson 2015). As based on performance and driving tests, this agent is known to produce a dose-related next day increase in somnolence for all age groupings tested (Farkus 2013). Sedative drug effects on daytime sleepiness are summarized in Table 4.

\section{Other agents inducing sedation}

Many other agents induce significant sedation as part of their clinical effect or as an untoward side-effect.
Clinically these agents are sometimes used off-label for their sedative effects. Among antihypertensives in wide use, the complaints of tiredness, fatigue and daytime sleepiness are commonly associated with drugs having antagonistic effects at the norepinephrine neuroreceptor (Dimsdale 1992). The complaints of tiredness, fatigue and daytime sleepiness (2-4.3\%) associated with beta-blocker use may occur secondary to disturbed sleep or direct action of the drug. Beta-blocking drugs with vasodilating properties (e.g. carvedilol, labetalol) are also associated with reported fatigue and somnolence (3-11\%). Sedation is among the most common side effects reported for the alpha- 2 agonists clonidine and methyldopa (30-75\%) (AHFS 2003). Alpha-1 antagonists (e.g. terazosin, prazosin) are sometimes associated with transient sedation. Prazosin, a norepinephine antagonist, has demonstrated value in treating insomnia associated with PTSD nightmares (Raskind et al. 2003). Clonidine is sometimes utilized to treat the agitation and insomnia that result from using amphetamines to treat $\mathrm{AD} / \mathrm{HD}$ in pediatric patients (Ming et al. 2011).

Sedation is a common side effect induced by anti-epileptic drugs, reported at levels of $70 \%$ with phenobarbitol, $42 \%$ with carbamazepine and valproate, and in $33 \%$ of patients using phenytoin and primidone

Table 4 Sedatives - Agents Used To Induce Sleep And Sedation With Significant Next Day Sleepiness After Used Based On Pharmacodynamics, Clinical Trials, And/Or Performance Testing

\begin{tabular}{|c|c|c|c|c|}
\hline CLASS (DRUG) [Neuromodulator Effected] & 1/2 LIFE & $\begin{array}{l}\text { Next Day Sleepiness } \\
\text { [Clinical Trials] }\end{array}$ & $\begin{array}{l}\text { Next Day Effects On } \\
\text { Performance \& Driving Tests }\end{array}$ & $\begin{array}{l}\text { Toxicity And/Or } \\
\text { Significant Side Effects }\end{array}$ \\
\hline $\begin{array}{l}\text { Antidepressants } \\
\text { - tricyclics (amitriptyline etc.) } \\
\text { [serotonin] }\end{array}$ & $10-20 \mathrm{HR}$. & Significant & $\begin{array}{l}\text { Significant With } \\
\text { Minimal Study }\end{array}$ & $\begin{array}{l}\text { Anticholinergic, } \\
\text { Respiratory suppression } \\
\text { in overdose }\end{array}$ \\
\hline $\begin{array}{l}\text { - Atypicals } \\
\text { (trazadone, mirtazapine) } \\
\text { [serotonin] }\end{array}$ & $\begin{array}{l}\text { traza- done ( } 8 \text { h) } \\
\text { mirtaza-pin } 20-40 \mathrm{HR} \text {. }\end{array}$ & Significant & $\begin{array}{l}\text { Significant With } \\
\text { Minimal Study }\end{array}$ & $\begin{array}{l}\text { Respiratory Suppression } \\
\text { In Overdose }\end{array}$ \\
\hline $\begin{array}{l}\text { H1 antihistamine } \\
\text { Diphinhydramine, } \\
\text { hydroxyzine, triprolidine) } \\
\text { [histamine] }\end{array}$ & $2-12 \mathrm{HR}$. & Significant & $\begin{array}{l}\text { Significant - } \\
\text { Multiple studies }\end{array}$ & $\begin{array}{l}\text { Confusion [Black Boxed } \\
\text { For The Elderly] }\end{array}$ \\
\hline $\begin{array}{l}\text { Antipsychotic } \\
\text { - Olanzapine } \\
\text { [histamine] }\end{array}$ & $6-8 \mathrm{HR}$ & Significant & $\begin{array}{l}\text { Significant with } \\
\text { minimal study }\end{array}$ & $\begin{array}{l}\text { Potentially persistent } \\
\text { extra-pyramidal } \\
\text { Side effects }\end{array}$ \\
\hline $\begin{array}{l}\text { - Doxepin } \\
\text { [histamine, orexin] }\end{array}$ & $\begin{array}{l}1 / 2-15 \mathrm{~h} \text {. (dose based) } \\
\text { active metabolite }\end{array}$ & Significant & $\begin{array}{l}\text { Significant With } \\
\text { Minimal Study }\end{array}$ & $\begin{array}{l}\text { Potentially persistent } \\
\text { extrapyramidal } \\
\text { Side effects }\end{array}$ \\
\hline $\begin{array}{l}\text { Gaba agonists } \\
\text { - medium } 1 / 2 \text { life benzodiazepi-nes } \\
\text { (estalolam, clonazepam, temezepam, etc.) } \\
\text { [GABA] }\end{array}$ & 7-10 HR. & Significant & $\begin{array}{l}\text { Significant } \\
\text { Multiple studies }\end{array}$ & Disinhibition \\
\hline $\begin{array}{l}\text { - Long } 1 / 2 \text { life benzodiazepi- nes } \\
\text { (flurezepam, diazepam, etc.) } \\
\text { [GABA] }\end{array}$ & Up To 11 Days & Significant & $\begin{array}{l}\text { Significant } \\
\text { Multiple studies }\end{array}$ & $\begin{array}{l}\text { Disinhibition } \\
\text { Falls in the elderly }\end{array}$ \\
\hline $\begin{array}{l}\text { Orexin antagonists } \\
\text { (suvorexant) } \\
\text { [orexin] }\end{array}$ & $10-22 \mathrm{HR}$. & Significant & Significant & $\begin{array}{l}\text { Unknown } \\
\text { New agent }\end{array}$ \\
\hline
\end{tabular}


(Schweitzer et al. 2003). In clinical trials sedation is reported as a side effect to treatment with topiramate $(15-27 \%)$ at at levels of $5-10 \%$ for gabapentin, lamotrigine, vigabatrin, and zonisamide (AHFS 2003). The neurochemical basis for the sedation induced by many of these agents remains poorly defined except for those agents know to have GABA agonist effects (e.g. gabapentin, phenobarbitol) (Westbrook 2000). Some drugs may act by glutamate antagonism and others by having direct effects on CNS electrophysiology (Pagel 1996). In individuals being treated with such medications for seizure disorders, the clinical differential between medication effects and sedation secondary to recurrent seizures can be difficult to determine (Manni and Tartara 2000).

Almost all drugs with CNS activity induce sleepiness as a side effect in some patients (Bittencourt et al. 2005; Guilleminault and Brooks 2001). The sedative side effects of some of these agents are clinically utilized in specific situations. However, sleepiness is a common and often-unwanted side effect for many types of prescription medications including commonly used antitussives, skeletal muscle relaxants, antiemetics, antidiarrheal agents, genitourinary smooth muscle relaxants, and others (Table 1). These sedative side effects can limit the use of these agents in patients in which the level of persistent daytime sleepiness affects waking. All sedating agents can contribute to an increased risk for motor vehicular accidents.

\section{Drug induced Hypersomnolence}

Drug induced hypersomnolence is a significant problem in today's society. Approximately $30 \%$ of traffic deaths in the United States can be attributed at least in part to the use of ethanol - the most commonly abused sedating medication (Department of Transportation (US), National Highway Traffic Safety Administration (NHTSA) 2015). Sedating drugs other than ethanol are contributing factors in 16\% of motor vehicular accidents (Berning et al. 2015).While not nearly as great a risk factor for driving as alcohol, marijuana may nearly double the risk of having a vehicle collision (Sewell et al. 2009). In the United States, marijuana users are about 25\% more likely to be involved in an MVA than drivers with no evidence of marijuana use (Compton and Berning 2015).

The prescription and OTC medications known to increase the risk of sleepiness-related crashes include longer acting benzodiazepine anxiolytics, sedating antihistamines ( $\mathrm{H} 1$ class), and tricyclic antidepressants (TCAs). The risks are higher with higher drug doses and for people taking more than one sedating drug simultaneously (Ceutel 1995; Gengo and Manning 1990; Van Laar et al. 1995). Since a high percentage of the population uses drugs of abuse as well as medications for underlying illness, the use of multiple sedating drugs use has increasingly become a problem. In 1993, about one in eight drivers were using more than one drug, but by 2010 , it was closer to one in five. The number of drivers dying in MVA's with three or more sedating drugs in their system increased from 11.5 to $21.5 \%$ during this period. Among drivers who tested positive for any drug, $48 \%$ also tested positive for alcohol (Disney et al. 2011).

\section{Comorbid insomnia}

The term secondary insomnia has historically been applied to patients with insomnia associated with either a medical or psychiatric condition or a primary sleep disorder. Until 2005 the NIH guidelines regarded such insomnia as being a consequence of the primary diagnosis. This led to recommendations that indicated the key was treating the primary or underlying condition with the assumption that this would, in turn, lead to resolution of insomnia. In 2005 the NIH convened another "State of the Science" conference to review the manifestations and management of chronic insomnia (NIH State of the Science Conference Statement on Manifestations and Management of Chronic Insomnia in Adults Statement, Journal of Clinical Sleep Medicine 2005). The committee concluded that most cases of insomnia are comorbid with other conditions. The concern over continuing to use the term "secondary" insomnia is that in many cases we do not have clear proof of cause and effect and, of greater concern; the use of the term may lead to under-treatment of insomnia. This recommendation to view insomnia as comorbid has to lead to a shift in treatment paradigms. While identification and treatment of the "primary" condition remain a priority, concurrent treatment of insomnia is now viewed as desirable. In general treatment of comorbid insomnia is now essentially the same as treating primary insomnia with a growing number of studies confirming that this approach is effective (Morin and Benca 2012; Sateia and Nowell 2004; Winkelman 2015). Treatment of insomnia can often improve the symptoms of the "primary" or a comorbid condition.

\section{Circadian system disturbances}

Sleep disorders related to circadian rhythm are caused by a misalignment of the approximately $24-\mathrm{h}$ endogenous circadian rhythm and the "normal" $24 \mathrm{~h}$ day/night cycle (Melatonin can act as a hypnotic and is a useful adjunct to treatment in individuals with circadian disturbance (Pandi-Perumal et al. 2008). Prescription synthetic analogs of melatonin such as ramelteon are available. Sleep tendency and reduced sleep latency are affected from $13 / 4-43 / 4$ h post ingestion (Stone et al. 2000). Melatonin has been used as a hypnotic with inconsistent results (Monti et al. 2013). The impact of this agent on next day performance is generally considered 
to be minimal. Next day psychomotor test results may not be affected, although one study has demonstrated significant effects on next day deviation of lateral position in driving tests (Mets et al. 2011).

Melatonin and light exposure have proven especially effective when used to treat Delayed Sleep Phase Syndrome most prevalent in adolescents and young adults (Pandi-Perumal et al. 2008). Patients with this syndrome have difficulty falling asleep at the desired bedtime, often falling asleep between 2 and 6 AM and then, if their lifestyle permits, sleeping approximately a normal $8 \mathrm{~h}$, awakening at between $10 \mathrm{AM}$ and $2 \mathrm{PM}$. Individuals with this common disorder often suffer from chronic insufficient sleep time with all its daytime consequences. Treatment involves exposure to bright light at the proper time in the circadian phase response curve. In the case of delayed phase syndrome, this is after the nadir of body temperature. Treatment with 10,000 lx for 30 min on awakening and timed melatonin administration in the early evening 3-6 $\mathrm{h}$ before sleep time (before the Dim Light Melatonin Onset (DLMO) or 12+ hours before the temper nadir are effective. Since melatonin can be soporific so caution needs to be exercised if used when the patient has wakeful activities to perform. Advanced Sleep Phase Syndrome (ASPS) is the mirror image of DSPS with patients sleep onset and awakening both several hours earlier than desired with the total sleep period remaining fairly normal. This is less common than DSPS and tends to occur more in middle-aged to elderly adults. Treatment options are similar to those for delayed phase syndrome with the timing of treatment designed to delay rather than advance the circadian rhythm. In shift workers, melatonin can be used to help shift the worker's circadian rhythm as required. When taken before bedtime in the early morning it can improve sleep quality. For individuals suffering from Jet Lag Disorder melatonin can be used to speed the adjustment to the new time zone (Brown et al. 2009; Srinivasan et al. 2010). Visually blind and incarcerated individuals can have non- $24 \mathrm{~h}$. and free-running circadian patterns that can be responsive to melatonin agonists such as tasimelteon (Neubauer et al. 2015).

Restless legs syndrome and periodic leg movement disorder Restless Legs Syndrome (RLS) is a common neurologic condition marked by the urge to move, particularly the legs, which occurs primarily at rest in the evening or bedtime. The essential criteria for making the diagnosis include: 1) The urge to move the legs, usually accompanied or caused by uncomfortable and unpleasant sensations in the legs; 2) The urge to move or unpleasant sensations begin or worsen with rest or inactivity; 3) The urge to move or unpleasant sensations are partially or totally relieved by movement; 4) The urge to move or unpleasant sensations are worse in the evening (Verma and Kushida 2014). Sleep disruptionand complaints of decreased quality of life is present in 3/4 of the patients with the syndrome (Allen and Earley 2001). A majority of RLS patients will have repetitive periodic limb movements (PLMS) on polysomnogram. The RLS/PLMD has a genetic basis and increases with age so that in the geriatric population (> 80 years) over $30 \%$ of individuals may meet criteria for the diagnosis. RLS/PLMD is also more common in children with $\mathrm{AD} / \mathrm{HD}$, patients in renal failure, individuals with low serum ferritin levels $(<50)$, and in patients taking some medications such including antidepressants, antiemetics and antihistamines (Phillips et al. 2006).

The treatment of the sleep disruption, primarily sleep onset, relies predominately on the treatment of the RLS rather than the treatment of resultant insomnia. Dopaminergic agonists have become the primary initial treatment for RLS. Pramipexole and ropinirole have both received FDA approval for this indication and are used in doses low relative to their use for Parkinson's Disease. Pramipexole is used in a range of 0.125 to $2 \mathrm{mg}$ and ropinirole at 0.25 to $4 \mathrm{mg}$. Dopaminergic agents, especially pramipexole, can induce significant somnolence as well as sleep attacks in some individuals (Micalief et al. 2009). Benzodiazepines have been used, historically clonazepam but also temazepam. There are no recent studies of the efficacy of these but historically they have been useful and still have a role when side effects limit the use of the dopaminergic agents or in combination in refractory cases. When lack of response or side effects are still present opioids with significant addictive potential in this situation such as codeine or oxycodone are sometimes utilized (Comella 2014). Gabapentin, and pregablin used off-label to treat RLS/PLMD induce significant hypersomnolence, interact with opiates, and have been described as drugs of abuse (Schifarno 2014). A varient of these agents, the alpha-2-delta ligand gabapentin enacarbil recently approved as a treatment for RLS is known to induce significant sedation and dizziness (Lee et al. 2011).

\section{Insomnia associated with sleep apnea and its treatment} Obstructive sleep apnea (OSA) induces daytime sleepiness in a significant percentage of affected individuals. Both apnea severity and the level of daytime sleepiness affecting waking function can be negatively affected by the concomitant use of sedatives - particularly opiates and ethanol (Pagel 2017). In a subset of individuals with OSA, breathing disruption contributes to disordered sleep and insomnia. The treatment of OSA with positive airway pressure (PAP) can improve sleep quality for such individuals (Nigram et al. 2017). However for others, PAP therapy can exacerbate insomnia (particularly in those patients with co-morbid PTSD) (Nigram et al. 2016). At altitude and in patients with concomitant 
heart failure, PAP therapy can induce the development of complex / central apnea - a diagnosis associated with significant complaints of insomnia (Pagel et al. 2011).

\section{Comorbid psychiatric disorders}

Psychiatric disorders commonly comorbid with insomnia include major depression, bipolar mood disorder, anxiety disorders, psychotic disorders, and amnestic disorders such as Alzheimer's disease. Estimates of the incidence of insomnia with these diagnoses are in the $50-75 \%$ range (Grandner and Perlis 2015). The most common psychiatric association is with the diagnosis of depression in which insomnia and depression have a circular or bidirectional relationship (Sateia and Nowell 2004). There are several studies that show that insomnia patients are at risk to develop depression. In a large study of young adults over a period of 20 years, 2 weeks of insomnia or longer predicted major depressive episodes and major depressive disorders (Buysse et al. 2008). Recurrent insomnia can also be the earliest sign that a patient in remission from their depression is at risk of a relapse (Breslau et al. 1996). Chronic insomnia problems may contribute to the persistence of depression. This issue is of particular importance in light of the significant rate of residual sleep disturbance in persons who have been otherwise successfully treated for depression (Ohayon and Roth 2003). Insomnia persisting after treatment of depression can be the most refractory symptom of depression. Drawing on data from a large interventional study of enhanced care for depressed elderly persons, the investigators found that persistent insomnia was associated with a 1.8 to 3.5 times greater likelihood of remaining depressed, compared with the population without continued sleep disturbance (Perlis et al. 1997). The relationship between insomnia and depression is further complicated by the fact that many common anti-depressants, especially the selective serotonin reuptake inhibitors (SSRI's), can induce disturbed sleep (McCrae and Lichstein 2001). In patients with insomnia and a psychiatric diagnosis treatment options include those also used for primary insomnia, either pharmacologic treatment, cognitive behavior treatment (psychological and behavioral) or a combination of both. Eszopiclone has been studied in patients with major depression along with the simultaneous use of fluoxetine (Fava et al. 2006). The combination was well tolerated and resulted in a rapid improvement in sleep. Of note, there was also a more rapid and larger antidepressant response. This does not suggest an antidepressant effect of eszopiclone but rather suggests that improved sleep has a beneficial effect on depression. This makes a strong case for the comorbid approach to treatment, simultaneous treatment of the two entities rather than the traditional approach of waiting for insomnia to improve as a result of treating depression. Combining treatment with antidepressants with cognitive-behavioral therapy for insomnia also demonstrated that the combined treatment was superior to the antidepressants alone both in terms of depression outcome $(61.5 \%$ vs $33.3 \%$ remission, respectively) and insomnia outcome (50\% vs $7.7 \%$ remission, respectively) (Manber et al. 2008). A similar result occurred with the use of eszopiclone with escitalopram for generalized anxiety disorder compared to the escitalopram alone (Pollack et al. 2008).

\section{Comorbid pain}

Chronic pain leads to poor sleep in a majority of patients (Cheatle et al. 2016). Pain can be an acute or chronic part of a broad range of medical ailments but most commonly cancer, rheumatologic disorders and headache. Chronic pain and sleep disruption produce a cycle of pain causing poor sleep and poor sleep leading to greater pain (Abad et al. 2008). Management is suggested as follows: diagnosis of the sleep problem, emphasis on sleep hygiene and then CBT techniques followed by pharmacologic interventions including medications for both pain and insomnia (Riemann and Perlis 2009) In rheumatologic disorders treatment of sleep with hypnotics or sedating antidepressants improves sleep but also improves pain tolerance. It should be noted that the United States is currently in the midst of an epidemic of opiate use that is resulting in a large number of deaths. Hypnotics have reduced side-effects, less addiction potential, and much lower toxicity than the opiates often used to treat chronic pain.

\section{Other comorbid medical conditions}

Patients with respiratory problems often have disruption of their sleep. COPD patients frequently have fragmented sleep (Crinion and McNicholas 2014). This can improve with oxygen if hypoxia is part of the problem. While Obstructive Sleep Apnea commonly induces daytime sleepiness, it can induce disturbed sleep as well (Talih et al. 2017). About a $1 / 3$ of asthma patients who are poorly controlled have nocturnal asthma attacks that interfere with their sleep and may lead to daytime symptoms. Patients with gastroesophageal reflux often have sleep disruption for the reflux. In addition, reflux can trigger asthma attacks in vulnerable patients. Patients with end-stage renal disease suffer from a variety of sleep disorders with a very high prevalence (Parish 2009). These can include insomnia, sleep apnea and a high incidence of secondary RLS. Menopause is associated with insomnia which can respond to treatment with hormones but also with treatment using a hypnotic (Soares et al. 2006). Chronic neurological conditions including Parkinsons disease are associated with significant insomnia, as are gastrointestinal disorders inducing 
pain and/or reflux, nocturia and enuresis, and other sleep associated disorders such as narcolepsy (Sateia et al. 2017).

The appropriate use of hypnotic and sedative medications Sedative/hypnotic agents were among the first known phamaceudical therapies. Many have had significant toxicities and side effects. Some with addictive potential have developed into major drugs of abuse that continue to negatively effect our modern society. For the physician addressing the patient complaint of insomnia, these agents can be difficult to appropriately utilize. This brief overview argues that today there are medications with very low toxicity, addictive potential, minimal next day sleepiness, and an otherwise benign side-effect profile that can be utilized safely and effectively to treat and improve function and quality of life for patients suffering from insomnia. These are the agents that should be exclusively classified as hypnotics and utilized as the first line of agents to induce sleep when medications are required to treat the complaint of insomnia (Table 3). The other pharmacological agents producing sedation (sedatives and others used off-label for sedative side-effects) should be used cautiously for the treatment of insomnia due to the increased risk of next day sleepiness as well as for known toxicities and adverse side effects (Tables $1 \& 4$ ).

\section{Abbreviations}

24h: twenty-four hour; AD/HD: attention deficit hyperactivity disorder; ASPS: Advanced sleep phase syndrome; BAC: Blood alcohol concentration; CBT: cognitive and behavioral therapies; CNS: Central nervous system; COPD: chronic obstructive pulmonary disease; CRF: corticotrophin releasing factor; DLMO: Dim light melatonin onset; DSPS: Delayed sleep phase syndrome; EEG: electroencephalography; EMG: electromyography; EOG: electrooculography; FDA: Federal drug administration; GABA: gamma amino-butyric acid; Hz: hertz; LD: Light dark; LD-50: lethal dose 50\%; $\mathrm{MCH}$ : melanin concentrating hormone; MVA's: Motor vehicular accidents; $\mathrm{NIH}$ : National Institute of Health; NREM: non-rapid eye movement; OSA: Obstructive sleep apnea; OTC: over the counter; PAP: positive airway pressure; PGD2: prostaglandin D2; PLMD: Periodic limb movement disorder; PLMS: periodic limb movements; PTSD: Post traumatic Stress Disorder; REM: Rapid eye movement; RLS: Restless Leg Syndrome;

SCN: suprachiasmatic nucleus; SSRI's: Selective serotonin reuptake inhibitors; TCAs: Tricyclic antidepressants; TNF a: tumor necrosis factor-a;

TRF: thyrotrophin releasing factor; VIP: vasoactive intestinal peptide

\section{Acknowledgements}

JF Pagel wishes to acknowledge the influence and training of Vernon Pegram PhD.

\section{Availability of data and materials}

Available and referenced.

\section{Authors' contributions}

All authors contributed to this text. All authors read and approved the final manuscript.

\section{Ethics approval and consent to participate}

The data included in this review article are from studies that met IRB approval for publication.

\section{Consent for publication}

You have the authors consent to publish.

\section{Competing interests}

The authors declare that they have no competing interests.

\section{Publisher's Note}

Springer Nature remains neutral with regard to jurisdictional claims in published maps and institutional affiliations.

\section{Author details}

${ }^{1}$ University of Colorado School of Medicine, Couthern Colorado Residency Program, Pueblo, CO, USA. ${ }^{2}$ Somnogen Canada Inc, College Street, Toronto, ON, Canada. ${ }^{3}$ School of Medicine Clinics Hospital, University of the Republic, Montevideo, Uruguay. ${ }^{4}$ Rocky Mountain Sleep, 1306 Fortino Blvd, Pueblo, CO 81008, USA

Received: 27 November 2017 Accepted: 24 May 2018

Published online: 06 June 2018

\section{References}

Abad VC, Sarinas PSA, Guilleminault C (2008) Sleep and rheumatologic disorders. Sleep medicine reviews 12(3)

Abbott S, Soca R, Zee P. Circadian Rhythm Sleep Disorders. In: Pagel J, PandiPerumal S, editors. Primary Care Sleep Medicine. 2nd ed. NY: Springer; 2014. p. 297-310.

Adam K, Oswald I. Can a rapidly-eliminated hypnotic cause daytime anxiety. Pharmacopsychiatry. 1989;22:115-9.

AHFS. Drug Information. Bethesda: American society of health-system pharmacists; 2003.

Allen $\mathrm{R}$, Earley $\mathrm{C}$. Restless leg syndrome: a review of clinical and neurophysiological features. J Clin Neurophysiol. 2001;18:128-47.

American Geriatrics Society. Updated beers criteria for potentially inappropriate medication use in older adults. J Am Geriatr Soc. 2015;63:1-20.

Berning A, Compton R, Wochinger K. Results of the 2013-2014 National Roadside Survey of alcohol and drug use by drivers. Washington, DC: NHTSA; 2015. (DOT HS 812 118). https://www.nhtsa.gov/sites/nhtsa.dot.gov/files/812118roadside_survey_2014.pdf. Accessed 2 June 2017.

Bhat A, Shafi F, Sohl A. Pharmacotherapy of insomnia. Expert Opin Pharmacother. 2008:9:351-62.

Bittencourt LR, Silva RS, Santos RF, Pires ML, Mello MT. Excessive daytime sleepiness. Rev Bras Psiquiatr. 2005;27(Suppl 1):16-21. http://www.scielo.br/ pdf/rbp/v27s1/en_24471.pdf

Blume WT. Drug effects on EEG. J Clin Neurophysiol. 2006;23(4):306-11. Review. PMID: 16885705

Borbély AA, Daan S, Wirz-Justice A, Deboer T. The two-process model of sleep regulation: a reappraisal. J Sleep Res 2016;25(2):131-143. doi: 10.1111/jsr. 12371. http://onlinelibrary.wiley.com/doi/10.1111/jsr.12371/epdf.

Breslau N, Roth T, Rosenthal L, et al. Sleep disturbance and psychiatric disorder: a longitudinal epidemiological study of young adults. Biol Psychiatry. 1996;39:411-8.

Brown GM, Pandi-Perumal SR, Trakht I, Cardinali DP. Melatonin and its relevance to jet lag. Travel Med Infect Dis 2009;7(2):69-81. doi: 10.1016/j.tmaid.2008.09.004.

Brown RE, Basheer R, McKenna JT, Strecker RE, RW MC. Control of Sleep and Wakefulness. Physiol Rev. 2012;92(3):1087-187. https://doi.org/10.1152/ physrev.00032.2011. http://physrev.physiology.org/content/92/3/1087.full.pdf

Buysse D, Angst J, Gamma A, Ajdacic V, Eich D, Rossler W. Prevalence, course, and comorbidity of insomnia and depression in young adults. Sleep. 2008;31:473-80.

Buysse DJ. In: Monk TM, editor. Drugs Affecting Sleep Sleepiness and Performance in Sleep sleepiness and Performance. West Sussex, England: John Wiley \& Sons; 1991. p. 4-31.

Carskadon M. Dement WC. Monitoring and Staging Human Sleep. In: Kryger MH, Roth T \& Dement WC, editors. Principles and Practice of Sleep Medicine. 5th ed. St. Louis: Elsevier Saunders; 2011. 16-26.

Cash SS, Halgren E, Dehghani N, Rossetti AO, Thesen T, Wang C, Devinsky O, Kuzniecky R, Doyle W, Madsen JR, Bromfield E, Eross L, Halász P, Karmos G, Csercsa R, Wittner L, Ulbert I. The human K-complex represents an isolated cortical down-state. Science. 2009;324(5930):1084-7. https://doi.org/10.1126/ science.1169626.

Ceutel C. Risk of traffic accident injury after a prescription for a benzodiazepine Ann Epidemiol. 1995;5(3):239-44.

Cheatle MD, Foster S, Pinkett A, Lesneski M, Qu D, Dhingra L. Assessing and managing sleep disturbance in patients with chronic pain. Sleep Med Clin. 2016;11(4):531-41. https://doi.org/10.1016/j.jsmc.2016.08.004.

Comella C. Treatment of restless leg syndrome. Neurotherapeutics. 2014;1 1:177-87. 
Compton RP, Berning A. Traffic Safety Facts Research Note: drugs and alcohol crash risk. Washington: NHTSA; 2015. Available at URL: http://www.nhtsa.gov/ staticfiles/nti/pdf/812117-Drug_and_Alcohol_Crash_Risk.pdf. Accessed 2 June 2017

Crinion SJ, McNicholas WT. Sleep-related disorders in chronic obstructive pulmonary disease. Expert Rev Respir Med. 2014;8(1):79-88. https://doi.org/ 10.1586/17476348.2014.860357. 24378218

Curry DT, Eisenstein RD, Walsh JK (2006) Pharmacologic Management of Insomnia: past, present and future. Psychiatric clinics of North America vol 29 \#4 .

Dai J, Swaab DF, Van der Vliet J, Buijs RM. Postmortem tracing reveals the organization of hypothalamic projections of the suprachiasmatic nucleus in the human brain. J Comp Neurol. 1998;400(1):87-102.

Department of Transportation (US), National Highway Traffic Safety Administration (NHTSA). Traffic Safety Facts 2014 data: alcohol-impaired driving. Washington: NHTSA; 2015. available at URL: http://www-nrd.nhtsa. dot.gov/Pubs/812231.pdf. (Last accessed June 02, 2017)

Dimsdale JE. Reflections on the impact of antihypertensive medications on mood, sedation, and Neuropsychologic functioning. Arch Intern Med. 1992; 152(1):35-9. https://doi.org/10.1001/archinte.1992.00400130061005.

Disney L, Pelkey S, Wipperman M, Yi H. from CSR; Caces F, Rank K, Zobeck T. from ONDCP (2011) Drug Testing and Drug-Involved Driving of Fatally Injured Drivers in the United States: 2005-2009. http://www.whitehouse.gov/ ondcp/drugged-driving.

Farkus R. Suvorexant safety and efficacy - FDA. 2013. www.fda.gov/downloads/... UCM354215.pdf. Accessed 2 June 2017.

Fava M, McCall W, Krystal A, Wessel T, Ruben R, Caron J, Amato D, Roth T. Eszopiclone co-administered with fluoxetine in patients with insomnia coexisting with major depressive disorder. Biological Psycyiatry. 2006;59:1052-60.

Finley J, Perlis V. Cognitive Behavioral Therapy of Chronic Insomnia. In: Pagel J, Pandi-Perumal S, editors. Primary Care Sleep Medicine. 2nd ed. NY: Springer; 2014. p. 67-82.

Gango F, Gabos C, Miller J. The pharmacodynamics of diphenhydramine-induced drowsiness and changes in mental performance. Clin Pharm \& Therapeutics. 1989;45(1):15-21.

García-García F, Acosta-Peña E, Venebra-Muñoz A, Murillo-Rodríguez E. Sleepinducing factors. CNS Neurol Disord Drug Targets. 2009;8(4):235-44. 19689305

Gengo F, Manning C. A review of the effects of antihistamines on mental processes related to automobile driving. J Allergy Clin Immunol. 1990;86:1034-9.

Grandner MA, Perlis ML. Treating insomnia disorder in the context of medical and psychiatric comorbidities. JAMA Intern Med. 2015;175(9):1472-3. https:// doi.org/10.1001/jamainternmed.2015.3015. 26147221

Guilleminault C, Brooks SN. Excessive daytime sleepiness: a challenge for the practising neurologist. Brain. 2001;124(Pt 8):1482-91. 11459741

Hajak G, Muller WE, Wittchen HU, Pittrow D, Kirch W. Abuse and dependence potential for the non-benzodiazepine hypnotics zolpidem and zopiclone: a review of case reports and epidemiological data. Addiction. 2003;98(10):1371-8.

Hauri P. (Task Force Chair) The international classification of sleep disorders diagnostic and coding manual (ICD-11), American Academy of sleep medicine (2005)

Heinrich M. Ethnopharmacology and Drug Discovery. In: Reference module in chemistry, molecular sciences and chemical engineering. New York: Elsevier; 2013.

Hermann WM, Schaerer E. Pharmaco-EEG: computer EEG analysis to describe the projection of drug effects on a functional cerebral level in humans. In: Lopes da Silva FH, Strom Van Leevwen W, Redmond A, editors. Handbook of electroencephalography and clinical neurophysiology. Vol. 2. Clinical applications of computer analysis of EEG and other neurophysiological signals. Amsterdam: Elsevier; 1986. p. 385-445.

Hofman MA, Zhou JN, Swaab DF. Suprachiasmatic nucleus of the human brain: an immunocytochemical and morphometric analysis. Anat Rec. 1996;244(4): 552-62. 8694290

Johnson K, Page A, Williams H, Wassemer E, Whitehouse W. The use of melatonin as an alternative to sedation in uncooperative children undergoing an MRI examination. Clin Radiology. 2002;57:502-6.

Krystal AD, Durrnace HH, Scharf M, Jochelson P, Rogowski R, Ludington E, Roth T. Efficacy and safety of doxepin $1 \mathrm{mg}$ and $3 \mathrm{mg}$ in a 12 week sleep laboratory and outpatient trial of elderly subjects with chronic primary insomnia. Sleep. 2013;33:1553-61.

Lee D, Ziman R, Perkins T, Poceta J, Walters A. A randomized, double-blind, placebocontrolled study to assess the efficacy and tolerability of gabapentin enacarbil in subjects with restless leg syndrome. J Clin Sleep Med. 2011;14:282.
Lewy AJ, Wehr TA, Goodwin FK, Newsome DA, Markey SP. Light suppresses melatonin secretion in humans. Science. 1980;210(4475):1267-9. 7434030

Lichstein K, Nau S, McCrae C, Stone K. Psychological and Behavioral Treatments for Secondary Insomnias. In: Kryger M, Roth T, Dement W, editors. Principles and Practice of Sleep Medicine; 2005.

Lossignol D. Euthanasia: medications and medical procedures. Rev Med Brux. 2008;29:435-40.

Mamdema JW, Danhof M. Electroencepalogram effect measures and relationships between pharmacokinetics and pharmachodynamics of centrally acting drugs. Clin Pharmacokinet. 1992;23:191-215.

Manber R, Edinger JD, Gress JL, San Pedro-Salcedo MG, Kuo TF, Kalista T. Cognitive behavioral therapy for insomnia enhances depression outcome in patients with comorbid major depressive disorder and insomnia. Sleep. 2008; 31(4):489-95

Manni R, Tartara A. Evaluation of sleepiness in epilepsy. Clin Neurophysiol. 2000; 111(suppl. 2):S111-4.

McCrae CS, Lichstein KL. Secondary insomnia: diagnostic challenges and intervention opportunities. Sleep Med Rev. 2001;5(1)

Medalie L, Cifu AS. Management of Chronic Insomnia Disorder in adults. JAMA. 2017;317(7):762-3. https://doi.org/10.1001/jama.2016.19004. 2824134

Mendelson WB. A review of the evidence for the efficacy and safety of trazadone in insomnia. J clin Psychiatry. 2005;66:469-76.

Mets MA, de Vries JM, de Senerpont Domis LM, Volkerts ER, Olivier B, Verster JC. Next-day effects of ramelteon $(8 \mathrm{mg})$, zopiclone $(7.5 \mathrm{mg})$, and placebo on highway driving performance, memory functioning, psychomotor performance, and mood in healthy adult subjects. Sleep. 2011;34(10):132734. https://doi.org/10.5665/SLEEP.1272.

Micalief J, Rey M, Eusebio A, Audebert C, Rouby F, Jouve E, Tardieu S, Blin O. Antiparkinsonism drug-induced sleepiness: a double-blind placebo-controlled study of L-dopa, bromocriptine and pramipexole in healthy subjects. British J Clin Pharm. 2009;87(3):333-40.

Ming X, Mulvey M, Moherty S, Patel V. Safety and efficacy of clonidine and clonidine extended-release in the treatment of children and adolescents with attention deficit and hyperactivity disorders. Adolesc Health Med Ther. 2011;2:105-12.

Monti JM, Monti D. Histamine $\mathrm{H}_{1}$ receptor antagonists in the treatment of insomnia. Is there a rational basis for use? CNS Drugs13; 2000. p. 87-96.

Monti JM, Torterolo P, Lagos P. Melanin-concentrating hormone control of sleep waking behavior. Sleep Med Rev. 2013;17:293-8.

Monti JM, Torterolo P, Pandi Perumal SR. The effects of second generation antipsychotic drugs on sleep variables in healthy subjects and patients with schizophrenia. Sleep Med Rev. 2016;33:51-7.

Morin CM. Psychological and Behavioral Treatments for Primary Insomnia. In: Kryger M, Roth T, Dement W, editors. Principles and Practice of Sleep Medicine; 2005.

Morin CM, Benca R. Chronic insomnia. Lancet. 2012;379(9821):1129-41. https:// doi.org/10.1016/S0140-6736(11)60750-2.

Morin CM, Espie C. Insomnia: a clinical guide to Assesment and treatment. New York: Kluwer Academic / Plenum Publishers; 2003. p. 101-19.

Morin LP. A Path to Sleep Is through the Eye (1,2,3). eNeuro. 2015;2(2) https://doi. org/10.1523/ENEURO.0069-14.2015. eCollection 2015 Mar-Apr

National Institue on Drug Abuse: National Institutes of Health. "Overdose Death Rates". Bethesda; 2015. https://www.ncbi.nlm.nih.gov/pmc/articles/ PMC4553644. Accessesd 4 Feb 2018.

Neubauer DN, BaHammam AS, Pandi-Perumal SR. Tasimelteon. Milestones in Drug Therapy. 2015;49:261-9. https://doi.org/10.1007/978-3-319-11514-6_13. https://link.springer.com/chapter/10.1007\%2F978-3-319-11514-6_13

Nigram G, Camacho M, Riaz M. Rapid eye movement sleep (REM) rebound on initial exposure to CPAP therapy: a systemic review and meta-analysis. Sleep Science and Practice. 2017;1:13.

Nigram G, Pathak C, Riaz M. A systemic review on prevalence and risk factors associated with treatment-emergent sleep apnea. Annals of Thoracic Medicine. 2016;11:202.

$\mathrm{NIH}$ State of the Science Conference Statement on Manifestations and Management of Chronic Insomnia in Adults Statement, Journal of Clinical Sleep Medicine (2005) 1, \#4, 412-421. https://consensus.nih.gov/2005/ insomniastatement.htm.

Norman JL, Anderson SL. Novel class of medications, orexin receptor antagonists, in the treatment of insomnia - critical appraisal of suvorexant. Nat Sci Sleep. 2016:8:239-47. https://doi.org/10.2147/NSS.S76910. eCollection 2016.

O'Hanlon JF, Ramaekers JG. Antihistamine effects on actual driving performance in a standard driving test: a summary of Dutch experience. 1989-94. Allergy. 1995;50:234-42. 
Ohayon MM, Roth T. Place of chronic insomnia in the course of depressive and anxiety disorders. J Pscyhiatr Res. 2003;56:497-502.

Oswald I. Sleep, New York, Penguin Books Ltd. ISBN. In: 9780140207439, vol. 13; 1970. p. 157.

Pabst MJ, Beranova-Giorgianni S, Krueger JM. Effects of muramyl peptides on macrophages, monokines, and sleep. Neuroimmunomodulation. 1999;6(4): 261-83.

Pagel JF. Pharmachologic alterations of sleep and dream: a clinical framework for utilizing the electrophysiological and sleep stage effects of psychoactive medications. Human Psychopharmachology. 1996;11:217-23.

Pagel JF (2017) Drug induced Hypersomnolence, in Hyperpersomnolence, A. S. BaHammam (Ed.) Sleep Med Clin. ;12(3):383-393.

Pagel JF, Kawiatkowski C, Parnes B. The effects of altitude associated central apnea on the diagnosis and treatment of OSA: comparative data from three different sites in the mountain west. J Clin Sleep Med. 2011;7(6):610-5

Pandi-Perumal SR, Trakht I, Spence DW, Srinivasan V, Dagan Y, Cardinali DP. The roles of melatonin and light in the pathophysiology and treatment of circadian rhythm sleep disorders. Nat Clin Pract Neurol. 2008:4(8):436-47. https://doi.org/10.1038/ncpneuro0847. Epub 2008 Jul 15. PMID: 18628753.

Parish J. Sleep-related problems in common medical conditions. Chest. 2009; 136(2):563-72.

Paul MA, Gray G, Kenny G, Pigeau RA. Impact of melatonin, zaleplon, zopiclone, and temazepam on psychomotor performance. Aviat Space Environ Med. 2003;74:1263-70.

Perlis ML, Giles DE, Buysse DJ. Self-reported sleep disturbance as a prodromal symptom in recurrent depression. J Affect Disord. 1997;42:209-12.

Phillips B, Hening W, Britz P, Manning D. Prevalence and correlates of restless leg syndrome: results from the 2005 National Sleep Foundation poll. Chest. 2006; 129:76-80.

Pollack M, Kinrys G, Krystal A, McCall WW, Roth T, Schaefer K, Rubens R, Roach J, Huang $H$, Krishnan R. Eszopiclone Coadministered with escitalopram in patients with insomnia and comorbid generalized anxiety disorder. Arch Gen Psychiatry. 2008;65(5):551-62.

Raskind MA, Peskind ER, Kanter ED, et al. Reduction of nightmares and other PTSD symptoms in combat veterans by prazosin: a placebo-controlled study. Am J Psychiatry. 2003;160(2):371-3.

Ray WA, Griffen MR, Downey W. Benzodiazepines of long and short elimination half life and the risk of hip fracture. JAMA. 1989;262:3303-7.

Rhyne DN, Anderson SL. Suvorexant in insomnia: efficacy, safety and place in therapy. Ther Adv Drug Saf. 2015:6(5):189-95. https://doi.org/10.1177/ 2042098615595359. https://www.ncbi.nlm.nih.gov/pmc/articles/PMC4591519/ pdf/10.1177_2042098615595359.pdf

Riemann D, Perlis ML (2009) The treatment of chronic insomnia: a review of benzodiazepine receptor agonists and psychological and behavioral therapies. Sleep medicine reviews. Vol 13(3).

Roehrs T, Carskadon MA, Dement WC, Roth T. Daytime Sleepiness and Alertness. In: Kryger M, Roth T, Dement W, editors. Principles and practice of sleep medicine. 3rd ed. Philadelphia: Saunders company; 2000. p. 43-53.

Sack RL, Auckley D, Auger RR, Carskadon MA, Wright KP, Vitiello M, Zhdanova IV. Circadian rhythm sleep disorders: part I, basic principles, shift work and jet lag disorders. Sleep. 2007;30(11):14841501.

Sateia MJ, Buysse DJ, Krystal AD, Neubauer DN, Heald JL. Clinical practice guideline for the pharmacologic treatment of chronic insomnia in adults: an American Academy of sleep medicine clinical practice guideline. J Clin Sleep Med. 2017;13(2):307-49.

Sateia MJ, Nowell PD. Insomnia. Lancet. 2004;364(9449):1959-73.

Schifarno F. Misuse and abuse of pregabalin and gabapentin, cause for concern? CNS Drugs. 2014;28:491-6.

Schutte-Rodin S, Broch L, BuysseD, Dorsey C, Sateia M. Clinical guideline for the evaluation and Management of Chronic Insomnia in adults. J Clin Sleep Med. 2008:4:487-504.

Schwartz JH. Neurotransmitters. In: Kandel ER, Schwartz JH, Jessell TM, editors. Principles of Neural Science. 4th ed. New York: McGraw Hill; 2000. p. 280-97.

Schweitzer PK, Muehlbach MJ, Walsh JK. MedicalDrugs affecting sleep, sleepiness and performance. Am J Geriatr Psychiatry. 2003;11:205-13.

Settle EC. Antidepressant drugs: disturbing and potentially dangerous adverse effects. J Clin Psychiatry. 1998;59(S16):25-9.

Sewell R, Poling J, Sofuoglu M. The effect of cannabis compared with alcohol on driving. Am J Addict. 2009;18(3):185-93. https://doi.org/10.1080/ 10550490902786934.
Soares CN,Joffe H, Rubens R, Caron J, Roth T, Cohen L (2006) Eszopiclone in patients with insomnia during perimenopause and early Postmenoause. Obstetrics and Gynecolgoy 108(6)

Srinivasan V, Singh J, Pandi-Perumal SR, Brown GM, Spence DW, Cardinali DP. Jet lag, circadian rhythm sleep disturbances, and depression: the role of melatonin and its analogs. Adv Ther. 2010;27(11):796-813. https://doi.org/10. 1007/s12325-010-0065-y. 20827520

Stone BM, Turner C, Mills SL, Nicholson AN. Hypnotic activity of melatonin. Sleep. 2000;23(5):663-70.

Swaab DF, Fliers E, Partiman TS. The suprachiasmatic nucleus of the human brain in relation to sex, age and senile dementia. Brain Res. 1985;342(1):37-44. 4041816

Talih FR, Ajaltouni JJ, Tamim HM, Kobeissy FH. Risk of obstructive sleep apnea and excessive daytime sleepiness in hospitalized psychiatric patients. Neuropsychiatr Dis Treat. 2017;13:1193-200. https://doi.org/10.2147/NDT. S131311. eCollection 2017.

Trauer M, Doyle J, Shantha M, Rajaratham D. Cognitive behavioral therapy for chronic insomnia: a systemic review and meta-analysis. Ann Intern Med. 2015;163:191-204.

Urade Y, Hayaishi O. Prostaglandin D2 and sleep/wake regulation. Sleep Med Rev. 2011;15(6):411-8.

Van Laar M, et al. Acute and subchronic effects of nefazodone and imipramine on highway driving, cognitive functions, and daytime sleepiness in healthy adult and elderly subjects. J Clin Psychopharmacol. 1995;15(1):30-40.

Verma N, Kushida C. Restless Legs and PLMD. In: Pagel J, Pandi-Perumal S, editors. Primary Care Sleep Medicine. 2nd ed. NY: Springer; 2014. p. 339-44.

Verster J, Volkerts E, Olivier B, Johnson W, Liddicoat L. Zolpidem and traffic safety - the importance of treatment compliance. Curr Drug Saf. 2007;2(3):220-6.

Verster JC, Volkerts ER, Schreuder AHCML, et al. Residual effects of middle-of-thenight administration of zaleplon and zolpidem on driving ability, memory functions, and psychomotor performance. J Clin Psychopharmacol. 2002;22: 576-83.

Vimal RL, Pandey-Vimal MU, Vimal LS, Frederick BB, Stopa EG, Renshaw PF, Vimal SP, Harper DG. Activation of suprachiasmatic nuclei and primary visual cortex depends upon time of day. Eur J Neurosci. 2009;29(2):399-410. https://doi. org/10.1111/j.1460-9568.2008.06582.x.

Volz HP, Sturm Y. Antidepressant drugs and psychomotor performance. Neuropsychobiology. 1995;31:146-55.

Westbrook G. Seizures and Epilepsy. In: Kandel ER, Schwartz JH, Jessell TM, editors. Principles of Neural Science. 4th ed. New York: McGraw Hill; 2000. p. 199-935.

White JM, Rumbold GR. Behavioural effects of histamine and its antagonists: a review. Psychopharmacology. 1988;95(1):1-14.

Wiler J, Bloomfield J, Woodworth G, Grant A, Layton T, Brown T, McKenzie D, Baker T, Watson G. Effects of fexofenadine, diphenhydramine, and alcohol on driving performance: a randomized, placebo-controlled trial in the lowa driving simulator. Ann Intern Med. 2000;132:354-63.

Winkelman JW. Insomnia Disorder. N Engl J Med. 2015;373(15):1437-44. https:// doi.org/10.1056/NEJMcp1412740. http://familymed.uthscsa.edu/residency08/ mmc/Insomnia_Disorder.pdf

\section{Ready to submit your research? Choose BMC and benefit from:}

- fast, convenient online submission

- thorough peer review by experienced researchers in your field

- rapid publication on acceptance

- support for research data, including large and complex data types

- gold Open Access which fosters wider collaboration and increased citations

- maximum visibility for your research: over $100 \mathrm{M}$ website views per year

At BMC, research is always in progress.

Learn more biomedcentral.com/submissions 